\title{
LA REPRESIÓN EN LA HISTORIA RECIENTE ARGENTINA: PERSPECTIVAS DE ABORDAJE, CONCEPTUALIZACIONES Y MATRICES EXPLICATIVAS
}

\author{
GABRIELA ÁGUILA (UNR / CONICET) \\ Escuela de Historia \\ Facultad de Humanidades y Artes \\ Universidad Nacional de Rosario \\ Consejo Nacional de Investigaciones Científicas y Técnicas \\ gbaguila@gmail.com
}

\section{Resumen:}

Este artículo analiza algunas de las perspectivas, conceptos y matrices explicativas más utilizadas e influyentes producidas en la Argentina entre los años iniciales de la transición democrática y la actualidad en particular en el ámbito académico, para analizar la represión en la historia reciente argentina: la noción de Estado terrorista, las perspectivas comparatistas y el concepto de genocidio.

\section{Palabras clave:}

Represión - Historia Reciente Argentina - Estado Terrorista - Perspectivas Comparadas Genocidio

\begin{abstract}
:
This article discusses some of the perspectives, concepts and most used and influential definitions produced between the early years of the democratic transition and today in Argentina to analyze the repression in recent history: the notion of terrorist state, comparatist perspectives and the concept of genocide.
\end{abstract}

\section{Keywords:}

Repression - Recent History in Argentina - Terrorist State - Comparatist Perspectives - Genocide 


\section{LA REPRESIÓN EN LA HISTORIA RECIENTE ARGENTINA: PERSPECTIVAS DE ABORDAJE, CONCEPTUALIZACIONES Y MATRICES EXPLICATIVAS}

GABRIELA ÁGUILA (UNR / CONICET)

gbaguila@gmail.com

\section{A modo de introducción. Sobre la violencia política y la represión en la historia argentina reciente}

Los análisis sobre la historia reciente y la memoria en la Argentina, producidos desde diversas matrices ideológicas, políticas y disciplinares, están atravesados por el problema de la violencia política y el terror de estado. El ejercicio de un inédito accionar represivo durante los años de la dictadura militar de 1976/83, tanto como el crescendo de violencia que marcó el período previo, explican tales énfasis.

Los estudiosos han apelado a interpretaciones de largo plazo que registran que la violencia política fue un rasgo de la historia del siglo XX -caracterizada por recurrentes golpes de estado y cíclicas interrupciones al orden constitucional-, como a miradas más centradas en la coyuntura que se extiende entre fines de los años '60 y mediados de los '70 cuando aquella se aceleró y/o profundizó, combinando una violencia de corte insurreccional con una creciente represión estatal y paraestatal. ${ }^{1}$

Gran parte de la atención se dirigió desde los inicios de la transición democrática y -sin perder centralidad- hasta nuestros días, hacia la última dictadura militar y la represión implementada en esos años, si bien la violencia política que la precedió ha sido en las últimas décadas uno de los ejes del debate público y político, más en lo que refiere a la acción de las organizaciones armadas que a la represión estatal y paraestatal. Y mientras para explicar la violencia post-golpe se desarrollaron distintas corrientes de interpretación o modos de conceptualizarla, para analizar la violencia política pre-golpe ha predominado una perspectiva más atenta a sus dimensiones o implicaciones ético-políticas que a su descripción e interpretación (y esto es especialmente válido para el accionar y el papel de las organizaciones político-militares). ${ }^{2}$

\footnotetext{
${ }^{1}$ Ese período estuvo caracterizado por una aguda movilización social y política y un proceso de radicalización contra el gobierno dictatorial instalado en 1966, que incluyó como ingrediente novedoso la aparición de organizaciones político-militares que eligieron la lucha armada como método de acción. La represión estatal y paraestatal se incrementó notablemente a partir de comienzos de los 70, con el objetivo de contrarrestar la actividad políticomilitar así como reducir la conflictividad social y política, denotando un contexto de violencia política creciente que tendría su cenit con el golpe de estado de marzo de 1976 y la instalación de una nueva dictadura. También se ha planteado que el golpe militar que derrocó al gobierno de Perón en 1955 fue el momento de inicio de prácticas políticas violentas, que se condensaron hacia fines de los años 60 cuando su uso se tornó "normal" y aceptado por buena parte de la sociedad. Vid. Romero, Luis Alberto, "La violencia en la historia argentina reciente: un estado de la cuestión”, en Pérotin-Dumon, Anne (dir.), Historizar el pasado vivo en América Latina, 2007, en línea en http://www.historizarelpasadovivo.cl/downloads/introargentina.pdf

${ }^{2}$ Esto es especialmente válido para el accionar y el papel de las organizaciones político-militares. Al respecto ver Vezzetti, Hugo, Sobre la violencia revolucionaria, Buenos Aires, Siglo XXI, 2009 y AA.VV., No matar. Sobre la responsabilidad, Córdoba, UNC / El Cíclope, 2007 y 2009. Para una perspectiva más atenta al análisis del período 1973/76 y la violencia estatal ver Franco, Marina, Un enemigo para la nación. Orden interno, violencia y "subversión”, 1973 1976, Buenos Aires, Fondo de Cultura Económica, 2012.
} 
En este punto es importante introducir una breve digresión de orden conceptual, ya que la utilización de los términos violencia política y represión requiere alguna puntualización. En palabras de Eduardo González Calleja, el concepto de violencia política es genérico y, en sus acepciones más comunes, aparece igualado o como muy cercano al de represión. Asimismo, tanto violencia como represión son conceptos valorativos, sometidos a los vaivenes del debate sobre su licitud o legitimidad. ${ }^{3}$

Registrar entonces la existencia de un creciente proceso de violencia política es a todas luces insuficiente si no se acompaña con la descripción y análisis de sus características, modos de ejercicio, actores, efectos, etc., evitando de este modo confundir o equiparar los diversos tipos de violencia política visibles en determinados contextos históricos. Así, y sin abordar la problemática de la legitimidad o no de la misma, la violencia insurgente o revolucionaria debe ser diferenciada de la represión, es decir, de la implementación de un conjunto de mecanismos coactivos por parte del estado (cualquiera sea su contenido de clase), sus aparatos o agentes vinculados a él para eliminar o debilitar la acción disruptiva de diversos actores sociales y políticos.

Desechando cualquier identificación simplista de las violencias de diversos tipos y signos que se verificaron en la historia reciente argentina tanto como una explicación omnicomprensiva anclada únicamente en "la Violencia" y su incremento, ${ }^{4}$ en esta ponencia nos proponemos analizar la problemática de la represión -el ejercicio de la violencia estatal y paraestatal en los '70 orientada a reprimir la conflictividad social y la violencia insurgente-, atendiendo en particular a sus dimensiones conceptuales y a los modos en los que se la ha definido. Nos centraremos en algunas perspectivas de análisis o matrices explicativas producidas entre los años iniciales de la transición democrática y la actualidad en particular en el ámbito académico, provenientes de diversos abordajes disciplinares y referidas en particular a la represión ejecutada en los años de la última dictadura militar.

\section{Breves consideraciones a propósito de los estudios sobre la represión}

Una cuestión que habría que apuntar es que en la Argentina aún es incipiente el desarrollo de una historiografía de la represión implementada en la segunda mitad del siglo XX (y en particular entre los años 60 y principios de los 80 ). Si bien es un elemento omnipresente en cualquiera de los trabajos sobre la dictadura de 1976/83, lo cierto es que no se ha desarrollado -o está en ciernes- una línea de investigación consolidada, nutrida de estudios sistemáticos sobre las características, contenidos y alcances del accionar represivo en los distintos ámbitos tanto durante los años de la dictadura como en el período precedente.

Esto no implica, por supuesto, afirmar que no existen estudios sino relevar algunas de las carencias y problemas que la temática involucra. A modo de introducción en la problemática señalaré algunas cuestiones que refieren, por un lado a las perspectivas y énfasis que han predominado y, por otro, a algunas líneas de renovación de este campo de estudios.

\footnotetext{
${ }^{3}$ Ver González Calleja, Eduardo, "La represión estatal como proceso de violencia política”, en Hispania Nova. Revista de Historia contemporánea, $\mathrm{n}^{\circ}$ 10, 2012, dossier: "De genocidios, holocaustos, exterminios... Sobre los procesos represivos en España durante la guerra civil y la dictadura", en línea en http://hispanianova.rediris.es/10, pág. 6.

${ }^{4}$ Que incluyen desde la teoría de los dos demonios o sus versiones remozadas, hasta perspectivas democratistas que han colocado a la violencia como antagónica de la política, condenando en bloque a "la violencia" de los años 70 y renunciando en gran parte a explicarla. Vid. Acha, Omar, "Dilemas de una violentología argentina: tiempos generacionales e ideologías en el debate sobre la historia reciente", Ponencia presentada a las $V^{o}$ Jornadas de Trabajo sobre Historia Reciente, UNGS, 2010, en línea en http://eltopoblindado.com/files/Articulos/07.\%20Lucha\%20 armada $\% 20 y \% 20$ violencia $\% 20$ politica $\% 20 /$ Acha, $\% 20$ Omar. $\% 20$ Violentolog $\%$ C3\%ADa $\% 20$ argentina.pdf. También Pittaluga, Roberto, "Miradas sobre el pasado reciente argentino. Las escrituras en torno a la militancia setentista", en Franco, Marina y Levín, Florencia (comps.), Historia reciente. Perspectivas y desafíos para un campo en construcción, Buenos Aires, Paidós, 2007.
} 
En primer lugar, que la mayor parte de los trabajos sobre el accionar represivo han analizado en particular el período abierto con el golpe de estado de marzo de 1976 y bastante menos los años previos. La explicación de tales énfasis no pasará desapercibida, ya que fue durante la dictadura de 1976/83 cuando la represión alcanzó proporciones y características inéditas, convirtiéndose en un elemento central en términos políticos, ideológicos y estratégicos del régimen militar. No menos significativas resultan las perdurables herencias de las violaciones a los derechos humanos, que se trasuntaron en luchas por la verdad y la justicia y en diversas políticas de memoria, reactualizando la problemática en el escenario público y político desde finales de la dictadura hasta el presente. ${ }^{5}$

En el caso específico de nuestro objeto, aunque se contaba con algunos estudios sobre la represión pre-golpe provenientes del ámbito académico, de memorias de ex militantes o de la investigación periodística, sólo recientemente el tema ha adquirido una mayor visibilidad en la indagación académica, reflejado en un conjunto de trabajos que dan cuenta de problemas poco analizados. ${ }^{6}$ A la vez se ha comenzado a poner en discusión la idea de ruptura o excepcionalidad que el golpe de estado representa, señalando en particular las continuidades existentes entre la represión pre y post-golpe y rediscutiendo las periodizaciones establecidas.

En segundo lugar, que es un tópico recurrente en la bibliografía sobre la problemática distinguir la violencia estatal implementada durante la dictadura y la represión registrada en los años previos, relevando los cambios sustantivos que implicaron el recurso sistemático de la desaparición de personas y la dinámica concentracionaria ${ }^{8}$. En esa dirección, gran parte de los estudios se han centrado en algunos de sus rasgos más salientes: el accionar clandestino de las fuerzas de seguridad, la desaparición de personas y las víctimas alojadas en centros clandestinos de detención localizados en unas pocas ciudades (en particular en la Capital Federal y la provincia de Buenos Aires), tanto como han referido a las memorias de los directos afectados y a las representaciones del terror de Estado. ${ }^{9}$ Sin obviar la centralidad de tales cuestiones mencionemos

\footnotetext{
${ }^{5}$ Esto no es excluyente para los estudios sobre la represión ya que, si nos situamos la historiografía del período, la mayor parte de los trabajos centrados en los años previos al golpe no avanzan sobre la dictadura, dando por sentado que ésta representó una clausura radical de los procesos previos y limitando las posibilidades de análisis de aquellos actores y procesos luego de marzo de 1976.

${ }^{6}$ Vid. Franco, Marina, Un enemigo para la nación..., op. cit. y "La 'seguridad nacional' como política estatal en la Argentina de los años 70", en Revista Antíteses, vol. 2, $\mathrm{n}^{\circ} 4$, en línea en http://www.uel.br/revistas/uel/index.php/antiteses; Rodríguez Agüero, Laura, "Mujeres en situación de prostitución como blanco del accionar represivo: el caso del Comando Moralizador Pío XII, Mendoza, 1974-1976", en Andújar, Andrea et al., De minifaldas, militancias y revoluciones. Exploraciones sobre los 70 en Argentina, Buenos Aires, Luxemburg, 2009; D’Antonio, Débora y Eidelman, Ariel, "El sistema penitenciario y los presos políticos durante la configuración de una nueva estrategia represiva del Estado argentino (1966-1976)", en Revista Iberoamericana, vol. X, $n^{\circ}$ 40, Madrid, 2010; Mazzei, Daniel, Bajo el poder de la caballería. El Ejército argentino (1962-1973), Buenos Aires, Eudeba, 2012, cap. 7; Ranaletti, Mario y Pontoriero, Esteban, "La normativa en materia de defensa y seguridad y la criminalización de las disidencias (1955-1976)", Ponencia presentada a las V Vornadas de Trabajo sobre Historia Reciente, UNGS, 2010.

${ }^{7}$ Aunque es posible rastrear algunos análisis tempranos que las detectaron (cfr. Marín, Juan Carlos, Los hechos armados. Argentina, 1973-1976. La acumulación primitiva del genocidio, PI.CA.SO./La Rosa Blindada, Buenos Aires, $1996-1^{\circ} \mathrm{ed}$. 1984-, más recientemente se ha enfatizado la idea de que la represión implementada a partir del golpe de Estado debe ser inscripta en un continum de prácticas, discursos y normativas represivas preexistentes.

${ }^{8}$ Véase, entre otros, Calveiro, Pilar, Poder y desaparición. Los campos de concentración en Argentina, Buenos Aires, Colihue, 1998, págs. 25-27 y Crenzel, Emilio, La historia política del Nunca más. La memoria de las desapariciones en la Argentina, Buenos Aires, Siglo XXI, 2008, cap. 1, págs. 23 y ss.

${ }^{9}$ Calveiro, Pilar, Poder y desaparición...op. cit; Crenzel, Emilio, La bistoria política..., op. cit.. Si bien la lista es extensa, véase da Silva Catela, Ludmila, No habrá flores en la tumba del pasado. La experiencia de reconstrucción del mundo de los familiares de desaparecidos, La Plata, Al Margen, 2001; Groppo, Bruno y Flier, Patricia (comps.), La imposibilidad del olvido. Recorridos de la memoria en Argentina, Chile y Uruguay, La Plata, Al Margen, 2001; Vezzetti, Hugo, Pasado y Presente. Guerra, dictadura y sociedad en la Argentina, Buenos Aires, Siglo XXI, 2002; Crenzel, Emilio (coord.), Los desaparecidos en la Argentina. Memorias, representaciones e ideas (1983-2008), Buenos Aires, Biblos-Latitud Sur, 2010; Gatti, Gabriel, Identidades desaparecidas. Peleas por el sentido en los mundos de la desaparición forzada, Buenos Aires, Prometeo, 2011. A ello debemos sumarle una nutrida literatura testimonial o de memorias de directos afectados por el accionar represivo,
} 
que, en estos últimos años, otros aspectos que no habían merecido tal atención han comenzado a ser estudiados, entre ellos el ejercicio de la violencia estatal en algunos espacios locales o regionales ${ }^{10}$ y otros sujetos o actores -y otras víctimas-, ${ }^{11}$ complejizando las miradas centradas en los desaparecidos y en algunas de las dinámicas y espacios, y contribuyendo a repensar la estrategia represiva implementada en distintas escalas y contextos.

En tercer lugar, que mientras investigadores provenientes de las ciencias sociales se ocuparon, desde perspectivas diversas y en distintos momentos, de analizar la represión ejecutada en la Argentina y de conceptualizarla, en la reconstrucción y documentación de algunas de las dinámicas del accionar represivo intervinieron actores y sectores ajenos a los espacios académicos. En particular, los organismos de derechos humanos (desde los años de la dictadura y hasta nuestros días) y, con altibajos, la justicia y el Estado y sus políticas de memoria.

Podemos postular con certeza que cualquier análisis sobre el ejercicio de la represión ejecutada en los años de la dictadura no podría eludir lo investigado por los organismos de derechos humanos y la Justicia en estas últimas décadas. En esos ámbitos no sólo se aportó a la investigación de los crímenes y/o a la construcción de un relato sobre el pasado que incluía centralmente las demandas de memoria, verdad y justicia, sino que también fueron parte del contexto donde se produjeron o difundieron algunas de las explicaciones más utilizadas para tipificar o definir la represión, articulándose de diversos modos con la producción académica. En tal sentido, un análisis que se centre en la reflexión intelectual sobre la represión deberá considerar estos recorridos y cruces entre el ámbito académico y extraacadémico.

\section{Sobre los conceptos y las definiciones: perspectivas de análisis y matrices explicativas}

Probablemente la definición que mayor difusión e influencia haya tenido para caracterizar y nominar al accionar represivo en la Argentina, sea la provista por un texto temprano, El Estado terrorista argentino, del jurista Eduardo Luis Duhalde. ${ }^{12}$

que incluyó a sobrevivientes de los centros clandestinos, ex presos políticos, exiliados o familiares de las víctimas y trabajos provenientes en su mayoría del periodismo de investigación.

10 Águila, Gabriela, Dictadura, represión y sociedad en Rosario. Un estudio sobre la represión las actitudes y comportamientos sociales en dictadura, Buenos Aires, Prometeo, 2008; Maneiro, María, Como el árbol talado. Memorias del Genocidio en La Plata, Berisso y Ensenada, La Plata, Al Margen, 2005; Izaguirre, Inés et al., Guerra civil, lucha de clases y genocidio en la Argentina. 1973-1983, Buenos Aires, Eudeba, 2009.

${ }^{11} \mathrm{Al}$ respecto ver Garaño, Santiago y Pertot, Werner, Detenidos-aparecidos. Presas y presos políticos de Trelew a la dictadura, Buenos Aires, Biblos, 2007; Merenson, Silvina y Garaño, Santiago (coords.), Dossier. La prisión política en la Argentina, entre la historia y la memoria (1966-1983), en Revista Iberoamericana, vol. X, n 40, 2010; D’Antonio, Débora, Cárceles en el estado terrorista argentino. Entre lo oculto y lo visible. Prácticas institucionales y experiencias de vida (1974-1983), Tesis doctoral inédita, Doctorado en Historia, Universidad de Buenos Aires, 2011; Yankelevich, Pablo (comp.), Represión y destierro. Itinerarios del exilio argentino, La Plata, Al Margen, 2004; Jensen, Silvina, La provincia flotante. El exilio argentino en Cataluña (1976-2006), Barcelona, Casa América Catalunya, 2007; Yankelevich. P. y Jensen, S. (coords.), Exilios. Destinos y experiencias bajo la dictadura militar, Buenos Aires, Libros del Zorzal, 2007; Franco, Marina, El exilio: argentinos en Francia durante la dictadura, Buenos Aires, Siglo XXI, 2008; Águila, Gabriela, "Testigos y vecinos: la dictadura en el Gran Rosario", en Revista Puentes, Año 6, N 19, 2007; Crenzel, Emilio, "Memorias y espacios de las violencias de Estado en Argentina: el caso del hospital Posadas", en Huffschmid, Anne (ed.), Topografias conflictivas: memorias, espacios y ciudad en disputa, Buenos Aires, Nueva Trilce, 2012; Sarrabayrouse Oliveira, María José, Poder Judicial y Dictadura. El caso de la Morgue, Buenos Aires, Editores del Puerto / CELS, 2011; Dicósimo, Daniel, "Dirigentes sindicales, racionalización y conflictos durante la última dictadura militar", en Revista Entrepasados, Año XV, n 29, 2006; Basualdo, Victoria y Lorenz, Federico, "Los trabajadores industriales argentinos en la primera mitad del '70: propuestas para una agenda de investigación a partir del análisis comparativo de casos”, en Páginas. Revista digital de la Escuela de Historia, vol. 4, $\mathrm{N}^{\mathrm{o}}$ 6, Rosario, 2012, en línea en http://web.rosarioconicet.gov.ar/ojs/index.php/RevPaginas/article/view/177.

12 Duhalde, Eduardo L., El Estado Terrorista Argentino. Quince años después, una mirada crítica, Buenos Aires, Eudeba, 1999 (1 ed. 1984). 
El estudio de Duhalde se produjo en el contexto de su militancia antidictatorial en el exilio español y en el seno de la Comisión Argentina por los Derechos Humanos (CADHU), vinculada a la recopilación de denuncias por las violaciones a los derechos humanos cometidas en la Argentina y las presentaciones en distintos foros internacionales. Su trabajo representó un jalón importante en la reflexión intelectual sobre el accionar represivo del gobierno militar y se articuló con otros emprendimientos de similar matriz. ${ }^{13}$ A la vez, fue un reflejo de la centralidad que adquirió el problema de la represión no sólo en la lucha antidictatorial, sino también en los análisis producidos en el exilio sobre la dictadura, desplazando otro tipo de abordajes. ${ }^{14}$

El libro se publicó en Argentina en 1984 y tuvo en ese año ocho reediciones, convirtiéndose en el de mayor venta en el país. Quince años después fue publicado con un nuevo título y un largo agregado inicial, donde el autor retomaba algunas de las reflexiones del primer texto, precisaba su caracterización e introducía elementos nuevos. ${ }^{15}$

Como han sostenido D'Antonio y Eidelman "fue el primer análisis de carácter global del modelo represivo en la Argentina", y se centraba en el estudio del Estado convertido en "terrorista" por el desarrollo de altísimas cuotas de violencia represiva y de una novedosa metodología criminal caracterizada por su faz clandestina y el uso permanente del terror. ${ }^{17}$

La tesis fundamental del texto es que este modelo de Estado era cualitativamente distinto de otras formas de autoritarismo estatal y representaba una nueva forma de Estado de excepción, con una doble faz: una pública y legal y una estructura paralela que denomina "Estado clandestino", que utiliza el terror permanente como método dirigido contra los ciudadanos, con el objetivo central de producir la desarticulación de la sociedad. ${ }^{18}$ La mirada de Duhalde, así como la de muchos de los estudiosos contemporáneos del fenómeno represivo, estaba centrada en el modelo de dominación estatal tanto como en su faz más novedosa y "original": la clandestinidad de las prácticas represivas.

13 Desde ese espacio se había producido otro texto, Argentina: proceso al genocidio (1977), donde se anticipaban algunas de las cuestiones sobre el accionar represivo que luego sistematizaría Duhalde. Un texto posterior, "El caso argentino: desapariciones como instrumento básico y generalizado de una política" firmado por Emilio Mignone (uno de los fundados del Centro de Estudios Legales y Sociales -CELS- y presentado en el Coloquio "La política de desapariciones forzadas de personas" realizado en Paris en 1981), recogería algunas de estas perspectivas desarrollando la idea del "paralelismo global" o de una normatividad paralela global y secreta donde se inscribía la desaparición masiva de personas (sin embargo, Duhalde planteará diferencias con esta perspectiva analítica en su libro). Ambos textos están disponibles en internet. Vid. Yankelevich, Pablo "Exilio y dictadura", en Crespo, Horacio, Lida, Clara y Yankelevich, Pablo (comps.), Argentina, 1976. Estudios en torno al golpe de Estado, Buenos Aires, Fondo de Cultura Económica, 2008; Mira Delli-Zotti, Guillermo y Esteban, Fernando O., "La construcción de un espacio político trasnacional iberoamericano de defensa de los DDHH: el caso de la Asociación Argentina Pro Derechos Humanos de Madrid", en HAOL, n 14, 2007. También Franco, M., El exilio..., op. cit. y Jensen, S., La provincia flotante..., op. cit.

${ }^{14}$ Nos referimos a los trabajos de algunos intelectuales marxistas exiliados en particular en México (Alberto J. Pla, Guillermo Almeyra, Alejandro Dabat, Adolfo Gilly), publicados durante la dictadura en revistas como la mexicana Cuadernos Políticos y, ya en los años iniciales de la democracia, en algunos volúmenes colectivos (Vid. AA.VV., La década trágica. Ocho ensayos sobre la crisis argentina. 1976-1983, Buenos Aires, Ed. Tierra del Fuego, 1984) o en la revista argentina Cuadernos del Sur (el primer número se publicó en 1985).

${ }_{15}$ Duhalde, E. L., El Estado Terrorista Argentino..., op. cit. El dato editorial mencionado se encuentra en la pág. 5 del citado libro.

${ }^{16}$ D'Antonio y Eidelman, "La historia reciente en Argentina: balance y perspectivas", ponencia presentada a las $X I^{\circ}$ Jornadas de Trabajo sobre Historia Reciente, Santa Fe, 2012.

17 Otro texto temprano, contemporáneo al de Duhalde, que se centraba en analizar el uso del terror como principal mecanismo de disciplinamiento social fue el de Juan Carlos Corradi ("El método de destrucción. El terror en la Argentina", en Quiroga, Hugo y Tcach, César (comps.), A veinte años del golpe. Con memoria democrática, Rosario, Homo Sapiens Ed., 1996 [1 $1^{\text {a }}$ versión 1982/83]). Sin embargo, con todo y su potencialidad como matriz explicativa de las relaciones entre sociedad y dictadura, tuvo una circulación muy restringida.

18 Así, analiza su estructuración, presupuestos y doctrina (seguridad nacional), metodología criminal (el circuito secuestro-tortura-desaparición), sus efectos multiplicadores a escala familiar y social y las luchas contra el terrorismo de estado. 
Si bien podría sostenerse que hay distinciones entre el concepto acuñado por Duhalde y los usos posteriores, ${ }^{19}$ lo cierto es que la noción de Estado terrorista -o de terrorismo de estado- está vinculada a algunas imágenes persistentes: la idea del ejercicio indiscriminado del terror sobre la sociedad (o sobre las víctimas), que opone a un Estado de actuación cuasi monolítica que ejerce el terror centralmente a través de prácticas clandestinas sobre el conjunto de una sociedad víctima, indiferenciada, inerme. Ello contribuyó a invisibilizar tanto el carácter selectivo de la represión y de sus víctimas o la variedad de acciones y dispositivos represivos (que incluyeron prácticas legales o cuasi-legales, normativizadas, visibles) o las tensiones y la fragmentación de las agencias estatales y paraestatales involucradas en la represión, como los comportamientos y actitudes sociales de consentimiento hacia el régimen militar y sus estrategias.

Como mencionamos, la noción de "Estado terrorista" fue, a partir de los inicios de la transición democrática, la definición o conceptualización más utilizada tanto entre los estudiosos de la dictadura como en el seno de los organismos de derechos humanos, la justicia y los "emprendedores" de memoria -probablemente desplazada, en los últimos años, por el amplio uso del término genocidio-. Y, como ha sucedido con otras conceptualizaciones o matrices explicativas del fenómeno, fue una definición tan profusamente citada como escasamente cuestionada o analizada críticamente. ${ }^{20}$

La otra vía de análisis que exploraremos refiere a una de las más transitadas en los estudios sobre la represión y la dictadura argentina: la comparación con otras experiencias dictatoriales, represivas o genocidas. Una perspectiva posible de rastrear en diversos emprendimientos analíticos realizados entre los años 80 y la actualidad, si bien los problemas y énfasis han variado.

Comenzaremos diciendo que en las ciencias sociales y políticas latinoamericanas no son una novedad las comparaciones o analogías con procesos históricos europeos así como la apelación a conceptualizaciones elaboradas para explicarlos. Sin abundar en los reiterados paralelismos establecidos por ejemplo entre los populismos latinoamericanos y el fascismo europeo, que constituyeron un tópico común en la bibliografía sobre este problema durante varias décadas, apuntaremos que en los años '70 la instalación de dictaduras militares en un conjunto de países del Cono Sur fue el nuevo escenario para la introducción de la "explicación fascista", sobre todo en los estudios producidos al calor de los acontecimientos. En el lenguaje político de la época (en particular de la izquierda), ${ }^{21}$ así como en los análisis de un heterogéneo conjunto de autores, se recurrió al término fascismo o sus homólogos para tratar de explicar el carácter de esos regímenes militares. ${ }^{22}$

Estas interpretaciones, que privilegiaban la dimensión represiva y el terror estatal como rasgo explicativo fundamental, fueron contestadas por quienes sostenían que las dictaduras instaladas

${ }^{19}$ Cfr. Feierstein, Daniel, "Sobre conceptos, memorias e identidades: guerra, genocidio y/o terrorismo de Estado en la Argentina", en Revista Politica y Sociedad, vol. 48, $\mathrm{n}^{\circ}$ 3, 2011, en línea en http://revistas.ucm.es/index.php/POSO/article/view/36417, págs. 159-160.

${ }^{20}$ Pilar Calveiro, (Poder y desaparición..., op. cit., págs. 135-137) le ha cuestionado su énfasis en la "inocencia" de las víctimas y Daniel Feierstein la falta de profundidad en algunas de sus aproximaciones (El genocidio como práctica social. Entre el nazismo y la experiencia argentina, Buenos Aires, Fondo de Cultura Económica, 2007, págs. 279-283).

21 Al respecto Águila, Gabriela, "El Partido Comunista Argentino entre la dictadura y la transición democrática (1976-1986)", en Revista de Historia Actual, no 6, Universidad de Cádiz, 2009, en línea en http://historiaactual.org/Publicaciones/index.php/rha/article/view/399/793, consulta: 9/10/13; también el artículo de Luciano Alonso contenido en este volumen.

${ }^{22}$ Referimos a un conjunto de trabajos que pretendieron adecuar el concepto a las condiciones latinoamericanas, entre ellos "fascismo dependiente", "fascismo sui generis", "militar-fascismo", "neofascismo". Veáse al respecto Zea, Leopoldo, "Fascismo dependiente en Latinoamérica", en Revista Nueva Politica, México, 1976; Cueva, Agustín, "La cuestión del fascismo", en Revista Mexicana de Sociología, no 2, 1977; Dos Santos, Theotonio, "Socialismo y fascismo en América Latina", en Revista Mexicana de Sociología, no 1, 1977; Marini, Ruy Mauro, Dos estrategias en el proceso chileno, México, ERA, 1978. 
en los años '70 no podían ser analizadas a la luz del fascismo europeo, requiriendo otros registros explicativos que dieran cuenta de sus especificidades. ${ }^{23}$

Muchos de estos trabajos se produjeron mientras los regímenes militares aún estaban en el poder y nutrieron la reflexión intelectual y académica en los años 80 y parte de los 90 , dominada por la preocupación por discutir el problema de la democracia y los procesos de transición de unos regímenes autoritarios hacia gobiernos democráticos y constitucionales. E interesa señalar, volviendo sobre la perspectiva comparativista, que la mayor parte de ellos estuvieron fuertemente permeados por una visión que inscribía a los golpes de estado y a las dictaduras en un ciclo histórico de carácter regional, medido en la simultaneidad de los procesos y en los rasgos que las definieron. ${ }^{24}$

Una segunda vertiente a reseñar, mucho más influyente en los análisis recientes sobre la dictadura y la represión, es la constituida por los estudios sobre la memoria. Si en el lenguaje político o en el espacio de los derechos humanos la equiparación de ciertos rasgos de las dictaduras con los fascismos -y, como veremos, con el Holocausto- fue temprana, el inicio de una reflexión más sistemática en el ámbito académico que incorporara la idea de la comparación con esos procesos hay que situarla hacia los años '90 y principios de la década del 2000, vinculada con el significativo desarrollo de la memoria como campo de estudios. ${ }^{25}$

Dichos abordajes privilegiaron las experiencias individuales y colectivas de hombres y mujeres involucrados en la militancia y las luchas de los años '60 y '70 así como las vivencias de los afectados por la represión implementada durante la dictadura militar, que incluyeron la desaparición de personas, la experiencia concentracionaria y los exilios. Estas últimas dimensiones colocaron a ese pasado reciente en el horizonte de análisis de los genocidios o los asesinatos en masa cometidos por el terror estatal, favoreciendo el énfasis comparativista.

Las experiencias europeas, en especial el Holocausto, funcionaron como un espejo desde el cual mirar a las décadas más recientes y a la última dictadura y sus herencias en el presente argentino, en sintonía con tendencias que se desarrollaban en otros ámbitos académicos. Sin embargo, las perspectivas y abordajes han sido diversos.

Mencionaremos brevemente que la comparación con el Holocausto se originó en los años de la dictadura militar, vinculada con la acción de organismos de derechos humanos que actuaban a

\footnotetext{
${ }^{23}$ En una perspectiva crítica, Alain Rouquié en su clásico libro sobre las dictaduras latinoamericanas se ocupaba de discutir tal caracterización para el pinochetismo (El Estado militar en América Latina, Buenos Aires, Emecé, 1984, págs. 299-302) y, en un artículo publicado a fines de los 70 y reeditado en los 90, Atilio Borón se ubicaba en el centro de ese debate señalando las diferencias entre el fascismo europeo y las dictaduras latinoamericanas ("El fascismo como categoría histórica: en torno al problema de las dictaduras en América Latina", en Borón, Atilio, Estado, capitalismo y democracia en América Latina, Buenos Aires, Imago Mundi, 1991). Véase también el artículo de Trindade, Helgio, "La cuestión del fascismo en América Latina”, en Revista Desarrollo Económico, vol. 23, n 91, 1983.

${ }^{24}$ Rouquieu, Alain, El Estado militar..., op. cit.; Borón, Atilio, Estado, capitalismo..., op. cit.; Trindade, Helgio, "La cuestión...", op. cit. Para la caracterización de las dictaduras militares ver además Garretón, Manuel, "Repensando las transiciones democráticas en América Latina”, en Revista Nueva Sociedad, n 148, 1997. Un artículo más reciente es el de Ansaldi, Waldo, "Matriuskas de terror. Algunos elementos para analizar la dictadura argentina dentro de las dictaduras del Cono Sur", en Pucciarelli, Alfredo (coord.), Empresarios, tecnócratas y militares. La trama corporativa de la última dictadura, Buenos Aires, Siglo XXI, 2004.

${ }^{25}$ Desde fines de los años 90 y comienzos de la década siguiente, la memoria se convirtió en un objeto de importante reflexión intelectual, dando lugar al surgimiento de un campo de estudios -la historia de la memoria o los estudios sobre la memoria-, con un significativo impacto en el panorama historiográfico argentino, en tanto se convirtió en una vía de entrada privilegiada para el análisis de muchos de estos procesos. He analizado estas cuestiones en Águila, Gabriela, "La Historia reciente en la Argentina: un balance", en Historiografías. Revista de bistoria y teoría, núm. 3, 2012, págs. 62-76, en línea en http://www.unizar.es/historiografias/numeros/3/aguila.pdf.
} 
escala trasnacional, ${ }^{26}$ a la vez que se difundió en medios judíos desde los inicios de la transición, emparentando a la dictadura con el nazismo por la persecución a ciudadanos de ese origen. ${ }^{27}$

Por diferentes caminos, esta identificación adquirió en los años posteriores otros contenidos y significaciones. La existencia de centros clandestinos de detención y, en general, las prácticas represivas equiparables con las utilizadas por los regímenes fascistas, ${ }^{28}$ los relatos de las víctimas, que exhibían importantes similitudes con aquellos producidos por los sobrevivientes de los campos de concentración nazis y el focalizar el análisis en las experiencias sociales (individuales y colectivas) frente a estas "situaciones límite", configuraron el marco en el cual la comparación con experiencias europeas y en particular con el Holocausto se volvió un tema recurrente y una alusión casi obligada en muchos de los estudios sobre la dictadura $-\mathrm{O}$ sobre la memoria de la dictadura- en la Argentina y otros países del Cono Sur. ${ }^{29}$

En estos estudios la perspectiva comparativista se asentó particularmente en el contrapunto entre las configuraciones de la memoria (social, colectiva) de los llamados pasados traumáticos y/o en la reflexión ensayística en torno al significado político y ético del terror estatal. ${ }^{30}$ La búsqueda de analogías remitió más a la relación entre "bistorias pasadas y memorias presentes" ${ }^{\text {"1 }} \mathrm{o}$ al nexo entre ese pasado traumático y el presente que al análisis del pasado en sí. ${ }^{32}$

Aunque, como hemos visto, los vectores de difusión de la vertiente comparatista fueron diversos, esta tendencia no puede desvincularse de los ecos de un debate que es extra argentino. Como ha sostenido Enzo Traverso el Holocausto se convirtió en el paradigma de la memoria del siglo XX, a partir del cual se interpretan, se analizan, se configuran las representaciones de otras formas de violencias, de otros genocidios, de otras crisis sociales y políticas. ${ }^{33} \mathrm{Al}$ tiempo que tampoco puede desvincularse de la profusa circulación de análisis que hacían foco en el Holocausto como

${ }^{26} \mathrm{Si}$ bien es conocido que el término genocidio titulaba hacia 1977 el informe de denuncia de las violaciones a los derechos humanos elaborado por la CADHU (Argentina: proceso al genocidio), Luciano Alonso ha registrado su temprana utilización en el seno de los organismos de derechos humanos, aún antes del golpe de estado de marzo de 1976 (vid. "La definición de las ofensas en el movimiento por los derechos humanos en Argentina y la calificación de 'genocidio", artículo contenido en este volumen).

${ }^{27}$ Debemos esta observación a la investigación de Emmanuel Kahan (Entre la aceptación y el distanciamiento: actitudes sociales, posicionamientos y memoria de la experiencia judia durante la última dictadura (1973-2007), cap. VI, Tesis doctoral inédita, Doctorado en Historia, Universidad Nacional de La Plata, 2001), quien sitúa hacia 1984 la equiparación dictadura / Holocausto y el inicio del debate sobre la comparabilidad.

${ }^{28}$ Destaca el multicitado libro de la socióloga y sobreviviente de la dictadura, Pilar Calveiro (Poder y desaparición..., op. cit.) quien recurre a un esquema de interpretación centrado en perspectivas teóricas elaboradas a propósito del genocidio nazi para analizar la experiencia concentracionaria argentina. También Martyniuk, Claudio, ESMA. Fenomenología de la desaparición, Buenos Aires, Prometeo, 2004.

${ }^{29}$ Cfr. los influyentes desarrollos de Elizabeth Jelin, condensados en su libro Los trabajos de la memoria (Buenos Aires, Siglo XXI, 2002), el primero de una serie de compilaciones denominada Memorias de la represión y el más polémico texto de un ensayista proveniente del psicoanálisis, Hugo Vezzetti, Pasado y Presente..., op. cit. También el libro antes citado de da Silva Catela y la compilación de Groppo y Flier. Es interesante señalar que Eduardo Luis Duhalde en la segunda edición de su libro El Estado Terrorista Argentino. Quince años después, una mirada crítica incluye "entre los antecedentes históricos de las desapariciones forzadas" las prácticas de la Alemania nazi, dedicando un largo apartado a la equiparación de aquellas con los decretos "Noche y Niebla" de diciembre de 1941 (op. cit., págs. 52 54). Consignemos, sólo a título ilustrativo, que esta idea no estaba en absoluto planteada en la versión publicada en los años 80.

${ }^{30}$ Para esta última perspectiva ver Vezzetti, Hugo, Pasado y presente..., op. cit. Su libro es probablemente el que exprese con más claridad la utilización de referencias teóricas elaboradas para analizar el Holocausto. Sin embargo, aunque advierte sobre el peligro de forzar analogías con el régimen nazi, gran parte de su construcción teórica se basa en esta perspectiva.

31 Jelin, Elisabeth, Los trabajos de la memoria, op. cit., pág. 74.

32 En tanto la mayor parte de estas perspectivas provenían de campos disciplinares ajenos a la Historia, en particular -aunque no exclusivamente- de la Sociología.

33 Vid. Traverso, Enzo, "Memoria, olvido, reconciliación. El uso público del pasado", en Lvovich, Daniel y Cernadas, Jorge (eds.), Historia ¿̇para qué? Revisitas a una vieja pregunta, Buenos Aires, Prometeo Libros / UNGS, 2010, págs. 51-52. 
"tropos de memoria", en las experiencias individuales y sociales frente al exterminio de masas, en las memorias y las representaciones. Así, las perspectivas de autores como Dominick LaCapra, Alessandro Portelli, Tzvetan Todorov, Jorge Semprún, Primo Levi, Michel Pollak o Giorgio Agamben, por solo citar algunos, se volvieron recurrentes para pensar la situación argentina.

El último marco conceptual que analizaremos se inscribe, en varios sentidos, en la perspectiva de los abordajes comparativos, si bien es posible seguir su genealogía en forma independiente. Nos referimos al uso y difusión del concepto genocidio para analizar lo acaecido en la Argentina en los años de la dictadura militar. Como ha analizado Luciano Alonso, la circulación del concepto no es nueva, en particular en el movimiento de derechos humanos. Sin embargo, su uso "académico" y sobre todo su difusión en distintos ámbitos sí reconocen una novedad en tanto se articulan a algunos emprendimientos intelectuales que reseñaremos.

En la Argentina el concepto apareció tempranamente en el espacio académico con los trabajos de Juan Carlos Marín y el grupo de investigación nucleado en el Centro de Investigaciones en Ciencias Sociales (CICSO) hacia los 80. Según este enfoque, el conflicto de clases exacerbado entre 1973/76 (un período de "guerra civil" y a la vez de "acumulación primitiva del genocidio") dará lugar al "genocidio" a partir del golpe de estado. ${ }^{34}$ En el caso de Marín el énfasis estaba puesto en analizar los años que precedieron a la dictadura, mientras que otra investigadora del grupo, Inés Izaguirre -junto con su equipo-, centró gran parte de sus indagaciones en el período dictatorial. ${ }^{35}$ En ambos desarrollos, el término aludía al exterminio de grupos, sin demasiada explicitación teórica y, aunque fue temprana en su utilización, esta vertiente conceptual tendrá poca influencia y difusión fuera de los investigadores del referido centro de estudios.

Recién en los últimos años el concepto adquirió una mayor densidad por dos vías diferentes, que reconocen algunas articulaciones: por el sistemático trabajo teórico del sociólogo Daniel Feierstein y por los recorridos judiciales, que incorporaron la categoría genocidio en los fundamentos de algunas sentencias a represores.

Los desarrollos que se verificaron en la Argentina en el ámbito académico no deben ser separados de la emergencia de los "Genocide studies" hacia la década del 90 (Marco, 2012). Esta línea de indagación se vinculaba, en primer lugar, con la comparación con el Holocausto y otros procesos genocidas verificados en diversos lugares del mundo, a la vez que el análisis de estos últimos se autonomizó de la dependencia de los estudios sobre el genocidio nazi. Sin embargo, el tratamiento de las dictaduras latinoamericanas en este marco de análisis fue bastante escaso hasta períodos más recientes (con la posible excepción del caso guatemalteco por el carácter étnico del exterminio).

Gran parte del trabajo de Feierstein se centró en definir y adecuar los alcances del concepto de genocidio para tipificar los crímenes ocurridos en la Argentina durante la dictadura militar. La exploración teórica y la reflexión comparada con el nazismo se articulan en su trabajo con la formulación de un marco conceptual específico para analizar la experiencia argentina: las "prácticas sociales genocidas".

En lo referido al ámbito judicial, en 2006 y por primera vez en el país, un tribunal condenó a un represor considerando que los delitos juzgados se encuadraban "en el marco del genocidio ocurrido en la Argentina entre 1976 y 1983". A partir de allí en otras jurisdicciones se incorporaría la misma figura

\footnotetext{
${ }^{34}$ Marín, J. C., op. cit. e Izaguirre, Inés, Los desaparecidos: recuperación de una identidad expropiada, Buenos Aires, C.E.A.L., 1994. Para un análisis de los desarrollos de Marín, véase Feierstein, Daniel, El genocidio como práctica social..., op. cit., cap. 7 y "Sobre conceptos, memorias e identidades...", op. cit.

35 Gran parte del trabajo del colectivo se ha centrado en analizar los perfiles socio-económicos y las adscripciones político-ideológicas de los desaparecidos, así como en avanzar en una cuantificación y caracterizar las modalidades regionales del genocidio. Cfr. Izaguirre, Inés et al., Guerra civil, lucha de clases y genocidio en la Argentina, op. cit.
} 
para enmarcar tales crímenes, ${ }^{36}$ a la vez que el término se propagó en los espacios vinculados a la memoria, los derechos humanos y la justicia.

Asimismo, se generalizó su uso no sólo para referir a los crímenes cometidos durante la dictadura militar sino para describir situaciones visiblemente diferentes. Al respecto, la noción más extendida es, de lejos, la de "genocidio económico", a la que se alude para referir a la exclusión social, producto de la aplicación de políticas de ajuste neoliberal. ${ }^{37}$

Si bien resulta difícil dilucidar donde se originó o planteó primero la utilización del concepto, lo cierto es que en este caso se verificó una infrecuente articulación de un desarrollo producido en las ciencias sociales con algunos recorridos judiciales, en tanto los planteos de Feierstein tuvieron una indiscutible repercusión en aquellos ámbitos. ${ }^{38}$

Ello no excluye que esa conceptualización haya generado muchas críticas en los espacios académicos, sin embargo el debate suscitado hasta el momento ha sido muy limitado: con la excepción del posicionamiento público de la socióloga Silvia Sigal a principios de la década del 2000 (cuando aún no se habían editado y circulado los principales trabajos de Feierstein) ${ }^{39}$ o algunas intervenciones alertando sobre los peligros de la homologación con el Holocausto, ${ }^{40}$ la mayor parte de las críticas se han reducido a notas al pie de página, menciones al pasar u objeciones solapadas al uso del concepto para tipificar lo sucedido en la Argentina.

Mencionaré brevemente que muchas de las impugnaciones al término genocidio se fundan en una lectura muy apegada a la formulación "clásica" del concepto acuñada en los años $40,{ }^{41}$ evitando

${ }^{36}$ Feierstein ha señalado que tanto en el proceso contra Pinochet como en los fallos del ex juez Baltasar Garzón y de la Audiencia Nacional española en 1998 y 1999 se reconocía la pertinencia de la calificación de genocidio para los hechos ocurridos en Chile y Argentina. Ver "El carácter genocida del Proceso de Reorganización Nacional", en Páginas. Revista digital de la Escuela de Historia, año 1, $\mathrm{n}^{\circ} 1$, 2008, en línea en http://web.rosarioconicet.gov.ar/ojs/index.php/revpaginas.

37 Esta utilización laxa del término genocidio para definir situaciones tan diversas ha sido uno de los aspectos más señalados para cuestionar su validez conceptual.

$38 \mathrm{El}$ autor ha señalado que sus contactos y debates con grupos de sobrevivientes influyeron en sus propios desarrollos teóricos. A la vez, los abogados querellantes utilizaron sus textos y los argumentos sobre el genocidio en causas que se tramitaron en La Plata, Santiago del Estero y Tucumán. Sin embargo, el Dr. Carlos Rozanski, juez federal de La Plata que intervino en el proceso referido de 2006, sostuvo en una intervención pública que los integrantes del tribunal se hallaban "desde antes" estudiando esa conceptualización para fundamentar la sentencia (declaraciones en el marco de la mesa redonda "Historia, justicia y diálogos. Los aportes del historiador al campo judicial, los caminos de la verdad y la prueba jurídica", $1^{\circ}$ Feria Argentina del Libro Universitario, La Plata, 02/09/2008). Aunque no lo trataremos in extenso, en los últimos tiempos se ha esbozado un debate sobre la viabilidad de la utilización del término en algunos sectores vinculados al movimiento de derechos humanos y en el ámbito judicial (en las causas por crímenes cometidos durante la dictadura militar), en tanto en muchos casos resulta dificultoso probar que el delito en cuestión se encuadre o tipifique como genocidio, retrasando u obstaculizando el accionar de la justicia.

39 Sigal sostuvo que la situación argentina y, más en general, las dictaduras latinoamericanas se diferenciaban de los genocidios en primer lugar por una dimensión cuantitativa ("se mide desde cientos de miles a millones de muertos") y en segundo lugar por el asesinato de personas por su condición étnica o religiosa. En contraste, las dictaduras latinoamericanas ( $\mathrm{y}$ en particular la argentina) se inscriben en la línea de las "masacres políticas", en tanto persiguieron y asesinaron personas por su pertenencia a un grupo político. Vid. "La polémica sobre el genocidio", en Revista Puentes, año 2, no 5, 2001.

40 Vid. Crenzel, Emilio, "La memoria de la desaparición de personas y el tropos del genocidio nazi", en CD Primer Encuentro Internacional "Análisis de las prácticas sociales genocidas", Buenos Aires, 2003. También Vezzetti, quien rechaza el término dado que "las víctimas fueron elegidas por razones políticas", prefiriendo hablar de masacre o exterminio planificados: "con ello trato de destacar la significación política de la tragedia de los desaparecidos y evitar que con la figura del genocidio la suerte de las víctimas quede asimilada a la de un grupo identitario situado al margen de la lucha política" (Pasado y presente..., op. cit., págs. 157-164; la última cita corresponde a la pág. 163).

${ }^{41}$ El concepto aparece en los años 40 de la mano de Raphael Lemkin, para quien genocidio es la "destrucción de una nación o grupo étnico" (el Holocausto es el paradigma del genocidio) y se sistematiza al final de la segunda guerra en la Convención para la Prevención y Sanción del delito de Genocidio en las Naciones Unidas: se entiende por genocidio los actos perpetrados con la intención de destruir, total o parcialmente, a un grupo nacional, étnico, racial o religioso, además la aniquilación o exterminio sistemático no es sólo física, sino también de su identidad cultural, 
justamente polemizar sobre las perspectivas que la ponen en discusión para poder incluir al caso argentino (v. g. los planteos ya citados de D. Feierstein). Alternativamente, se han centrado más en la definición abstracta del término o en sus dimensiones jurídicas (¿los crímenes cometidos en la Argentina compatibilizan más con un genocidio o deben ser tipificados como delitos de lesa humanidad?), que en discutir su pertinencia para el análisis de específicas situaciones históricas.

Soslayan así algunos problemas más significativos que el concepto posee: su matriz jurídica, que lleva a superponer o confundir los territorios entre historia y justicia restándole densidad al análisis empírico-conceptual; ${ }^{42}$ el erigirse en un modelo de referencia ("el paradigma del genocidio") en el que hay que encajar los procesos analizados; ${ }^{43}$ y -aquí se acerca a la noción de terrorismo de estado-, en caracterizar el accionar represivo ejecutado en la Argentina como un programa completo de exterminio que se ejerce "desde arriba" y sobre una población inerme (sin comprender sus matices, variaciones locales y regionales, la disparidad de prácticas, fuerzas actuantes y víctimas, los diversos comportamientos sociales, etc.).

\section{Reflexiones finales}

Un rasgo reiterado en los estudios sobre la última dictadura (y no exclusivamente en los que se han ocupado de la represión), refiere a la utilización en general indistinta de un conjunto de términos para definir las acciones llevadas adelante por el gobierno militar o las fuerzas represivas: violencia, terrorismo de estado, represión, genocidio, exterminio masivo, las más de las veces sin precisar su uso ni hacer explícitos los marcos teóricos desde donde se producen o utilizan tales definiciones. Soslayan así la existencia de un debate conceptual o, en todo caso, el hecho de que muchos de esos términos están cargados de diversos sentidos que no siempre se hacen evidentes.

Quizás convenga insistir con la afirmación de que en la Argentina casi no ha habido polémicas sobre los modos de definir o conceptualizar el accionar represivo ejecutado durante los años de la dictadura, a excepción probablemente del uso reciente del término genocidio. Y en este último caso se trata de una polémica velada.

Ello probablemente se deba a la potencialidad explicativa de algunas de estas nociones, en particular la de Estado terrorista, tanto como a la favorable y extendida recepción que tuvo la comparación con otros procesos represivos a gran escala (con otros genocidios o exterminios de masas) cometidos por diversos regímenes autoritarios en distintos lugares y momentos del siglo XX.

Aunque muchas veces el uso de estas vías de análisis se encuentre recorrido por dos tipos de tentaciones o problemas: por un lado, la reproducción de explicaciones modélicas y/o de visiones monolíticas de la dominación estatal y su accionar que limitan la posibilidad de dar cuenta de las variaciones del ejercicio de la represión (que detallábamos más arriba) o que se centran en algunas de sus características (aquellas "originales" del caso argentino: la desaparición de personas, la clandestinidad del accionar, la centralización a escala nacional del exterminio, el rol clave del Ejército) desplazando o invisibilizando la centralidad de otras modalidades, dispositivos

simbólica, etc. El debate posterior respecto del término refiere a lo que deja fuera, en particular a los grupos políticos, abriéndose una discusión sobre la necesidad de incluirlos dentro de la tipología de los genocidios, o acuñándose la noción de politicidio o limpieza política. Al respecto ver el concienzudo estudio de Jorge Marco, “Genocidio y 'genocide studies': definiciones y debates", en Hispania Nova. Revista de Historia Contemporánea, n’ 10, 2002, Dossier, en línea en http://hispanianova.rediris.es/10.

${ }^{42}$ Marco, Jorge, "Genocidio y 'genocide studies'...", op. cit.

43 Alonso, Luciano, "La definición de las ofensas...", op. cit., ha señalado que "los estudios sobre el genocidio suelen postular secuencias que van de la construcción de una otredad negativa a la realización simbólica. Luego, sólo resta ver la inclusión de los 'casos' en la tipología y aplicar la periodización resultante, o sea encajar la realidad en la horma de la teoría con sus correspondientes salvedades”. 
represivos y víctimas. Y, por otro, la homologación con otros procesos históricos (centralmente las experiencias fascistas europeas y en particular el Holocausto), a veces sin conocer en profundidad la dinámica política y social de los fenómenos comparados, resultando frecuentemente en una repetición vacua de perspectivas con una gran riqueza analítica.

Conviene apuntar que la producción académica sobre estas problemáticas ostenta un carácter desigual en la articulación entre la dimensión conceptual o teórica y los análisis empíricos. Así, estudiar la represión no implica necesariamente que ese abordaje esté asociado a un esfuerzo por conceptualizarla y, en contraste, la teorización en torno al accionar represivo no siempre ha ido acompañada por un análisis empírico de la problemática.

Como hemos planteado en este trabajo, en las últimas décadas se han formulado un conjunto de interpretaciones o conceptualizaciones sobre la represión (aquí hemos desarrollado las más influyentes y difundidas), con distinta densidad teórica o potencialidades explicativas. Gran parte de esos desarrollos analíticos y teóricos provinieron en particular de la sociología, la ciencia política o el derecho, en un contexto donde la Historia como disciplina llegó tardíamente al estudio de estas temáticas. Este retraso probablemente explique que los trabajos historiográficos hayan sido muy receptivos o permeables a las conceptualizaciones provenientes de otras matrices disciplinares, en tanto dichas categorías o conceptos ya estaban fuertemente arraigados en diversos ámbitos (en el movimiento de derechos humanos, en los actores vinculados a emprendimientos de memoria, en la justicia) tanto como en los espacios académicos.

Esos amplios consensos respecto de la utilización de ciertas categorías de análisis, se registran también en las descripciones dominantes del accionar represivo, vinculadas sobre todo -aunque no exclusivamente- con los recorridos y estrategias judiciales en las causas por delitos de lesa humanidad. Estas perspectivas -tempranamente reconstruidas y documentadas por los organismos de derechos humanos y trabajos como los de Duhalde, así como por la CONADEP-, destacan la sistematicidad de la política de exterminio dirigida centralizadamente por las Fuerzas Armadas y portadora de características estructurales comunes ${ }^{44}$ y aplicadas a escala nacional a través de todos los aparatos y recursos del Estado (tanto en su faz clandestina como en la normativa jurídico-legal que avaló el plan de exterminio).

Así, cuando se analiza el accionar represivo en el período abierto con el golpe de estado, se apunta a señalar la articulación existente entre los diversos ámbitos, organismos y fuerzas involucradas, concebidos y descriptos como engranajes más o menos indiferenciados de una misma maquinaria represiva organizada y dirigida por las Fuerzas Armadas. La actuación autónoma y diferenciada de los distintos dispositivos y fuerzas represivas preexistente habría sido eliminada por efecto de un proceso de "militarización", subsunción o subordinación de aquellos a los objetivos y mandos militares, homogeneizando métodos y prácticas represivas.

Aún sin contradecir de plano estas perspectivas, los contados estudios sobre algunos de esos ámbitos (las cárceles, e incluso el aparato judicial) así como las indagaciones sobre el accionar represivo en ciertos espacios regionales o locales, dan indicios de la existencia de lógicas, prácticas y modos de actuación con características diferenciadas -e incluso con ciertos grados de autonomía así como de tensiones y conflictos entras las distintas fuerzas intervinientes-, cuyo análisis requiere ser profundizado. En ese sentido, todavía está por hacerse una historia que pueda dar cuenta de las modalidades de acción de los distintos organismos y fuerzas represivas (policías, gendarmería, servicios de inteligencia, militares), atendiendo tanto a esas especificidades como a las tramas que los articularon.

\footnotetext{
${ }^{44}$ Que incluyeron: la definición del "enemigo" a aniquilar, el "delincuente subversivo", una categoría amplia y con fronteras difusas; una metodología operativa constituida por el circuito secuestro - reclusión de las víctimas en Centros Clandestinos de Detención - utilización sistemática de la tortura sobre los prisioneros - liberación (o reclusión en cárceles comunes) o asesinato con ocultamiento del cadáver, es decir, la desaparición de personas; así como otro tipo de acciones criminales, entre las que destaca la apropiación de menores nacidos en cautiverio.
} 
Aunque comienza a esbozarse una preocupación por discutir algunas de las conceptualizaciones dominantes respecto de la represión, conviene señalar que si existe una carencia es la que refiere a la realización de estudios de caso, con densidad empírica, que den cuenta de las características y modalidades del accionar represivo en los años pre y post golpe de estado y en los distintos escenarios, permitiendo construir un "cuadro completo" del ejercicio de la represión. En resumen, la formulación de perspectivas de análisis y teorías explicativas sobre la violencia política y la represión estatal que se generalizó en los años 70 requiere acompasarse con la producción de estudios históricos (empíricos, descriptivos, analíticos), con el objetivo adicional de poner en discusión la validez explicativa de aquellos marcos teórico-conceptuales. 